\title{
Development of a Low-Cost Air Quality Data Acquisition IoT-based System using Arduino Leonardo
}

\author{
Louis Anton A. Cruz ${ }^{\mathrm{a}}$, Maria Teresa T. Griño ${ }^{\mathrm{a}}$, Thea Marie V. Tungol ${ }^{\mathrm{a}}$, Joel T. Bautista ${ }^{\mathrm{a}}$ \\ ${ }^{a}$ Philippine Science High School - Central Luzon Campus, Pampanga, 2009, Philippines
}

Received: 17 November 2018; Accepted: 15 February 2019; Published: 08 May 2019

\begin{abstract}
Air pollution is responsible for an estimated 5.5 million deaths in 2013 which costed the global economy approximately US $\$ 225$ billion in lost labor income. To address the problems caused by air pollution, this study aims to develop a low-cost and portable air quality monitoring system that detects the levels of CO, PM2.5, PM10, temperature, and humidity. Using Internet of Things (IoT), the data that the system gathers can be accessed through the internet. Moreover, the system assesses the obtained data through a comparative analysis with the AQI. The Iterative Design Loop method was used in the development of the air quality monitoring system. Furthermore, the sensors were programmed using the Arduino Integrated Development Environment (IDE). Using the Welch's t-test, it was found that the obtained data of the system is not significantly different to that of the standard air quality monitoring systems. To achieve more accurate data from the developed system, the raw data of the developed and standard system were calibrated through an equation from the trendline. Through the use of Acer CloudProfessor, the study successfully developed an air quality monitoring system that can be accessed through the internet.
\end{abstract}

Index Terms: Air Quality Index, Arduino Leonardo, Internet of Things.

(C) 2019 Published by MECS Publisher. Selection and/or peer review under responsibility of the Research Association of Modern Education and Computer Science.

\section{Introduction}

In recent years, researches focusing on developing a low-cost air quality monitoring system using a wireless sensor network (WSN) Arduino microcontroller have been gaining attention. This is because air pollution is responsible for an estimated 5.5 million deaths in 2013 which costed the global economy approximately US\$225 billion in lost labor income [1]. In the Philippines alone, 1 out of 4 deaths is associated with air pollution [2]. Moreover, the inefficient combustion of transport fuels, power generation, and other human

* Corresponding author.

E-mail address: 
activities result to pollutants such as carbon monoxide (CO), particulate matter (PM), and various gaseous and particle-bound toxic compounds [3].

The air quality index (AQI) is a scale used in determining the air quality of an area. It focuses on the health effects that may be experienced within a few hours or days after the inhalation of the polluted air. Moreover, the Internet of Things (IoT) is a network of small, low-cost, low-power, ubiquitous electronic devices which sense data and communicate information without direct human intervention [4]. An advanced middleware specifically a WSN is needed to mask the heterogeneity of these things [5]. The utilization of a WSN is costefficient for it removes the cost of installation and maintenance [6].

Air pollution is an important environmental issue in developing countries such as the Philippines. It affects the respiratory and cardiovascular system and also causes environmental effects such as acid rain, haze, ozone depletion, and global climate change [7]. As there is no air quality monitoring system in the Philippines which provides an easily accessible data, this study is of great significance for it presented an air quality monitoring system equipped with a WSN; thus, the data that the developed system provides may be accessed through the internet. Moreover, the system is cost-efficient since as compared to the DOAS system of DENR-EMB which costs Php 3,000,000.00 [8], the developed system only costed Php 17,605.00. Furthermore, the inhabitants of the area of assessment were informed about the health effects of the air quality of their area and the actions that should be taken to improve it.

To address the problems caused by air pollution, this study developed a low-cost and portable air quality monitoring system that detects the levels of CO, PM, temperature, and humidity. In addition, the data that the system gathers is accessible through the internet. Moreover, the systems assesses the obtained data through a comparative analysis with the AQI. It is believed that the development of this system will help communities better assess the air quality of their area.

\section{Literature Review}

\subsection{Air Pollution}

Air pollution is one of the most crucial environmental problems in many developing nations. Yearly, air pollution is accountable for a significant number of deaths worldwide which are mostly caused by respiratory and cardiovascular diseases. In 2013, 5.5 million deaths due to air pollution were recorded. [1] Short-term exposure to increased levels of air pollution is associated with an increased risk of myocardial infarction, stroke, and acute heart failure [2] Furthermore, Korten, Ramsey, \& Latzin (2016) found that prenatal exposure to air pollution can impede organogenesis that can lead to long-term complications. Moreover, subjection to air pollution during pregnancy is related to decreased lung function in infancy, increased respiratory symptoms, and development of childhood asthma.

The six common air pollutants stated by the Environmental Protection Agency [3] are carbon monoxide, particulate matter, nitrogen dioxide, sulfur dioxide, ozone and Lead [4]. These pollutants pose harmful effects on humans and the environment considering their concentration in the atmosphere.

\subsection{Carbon Monoxide}

$\mathrm{CO}$ is one of the most common toxic gases that contribute to air pollution in the atmosphere [9] Moreover, Chen (2011) stated that CO is significantly correlated with non-accidental and cardiovascular mortality. Furthermore, $\mathrm{CO}$ is associated with impaired neurodevelopmental outcome [9].

\subsection{Particulate Matter}

PM is a mixture of soot and other liquid and solid-phase materials. The formation of soot occurs in regions 
where fuel is abundant, temperature is elevated, and oxygen concentration is insufficient. PM comes from both human and natural sources. Natural sources comprise sea salt, forest fires, pollen, and mold. These are harder to control as compared to human sources which can be regulated[10]. With this, PM may be subdivided into two types according to its effective aerodynamic diameter: $\mathrm{PM}_{2.5}$ and $\mathrm{PM}_{10}$ [9]. $\mathrm{PM}_{10}$ is a $\mathrm{PM}$ having an effective aerodynamic diameter smaller than $10 \mu \mathrm{m}$ [9]. It is one of the most dangerous pollutants in the atmosphere. This is because high levels of $\mathrm{PM}_{10}$ is correlated to the rise in hospital admissions for respiratory and cardiovascular diseases [10]. $\mathrm{PM}_{2.5}$ is a PM with an aerodynamic diameter below $2.5 \mu \mathrm{m}$. It comes from fuel burning, industrial combustion processes, and vehicle emissions. In addition, it has a greater negative effect to the human health than that of the $\mathrm{PM}_{10}$ as it can pierce more deeply in the respiratory system since it is smaller in diameter [9].

\subsection{Air Quality Index}

The Environmental Protection Agency (EPA) aims to "protect human health and the environment" (United States Environmental Protection Agency, 2017). One of the major topics of environmental issues it is concerned with is the condition-- how clean or polluted-- of air. Some ways to measure air quality is by using the Air Quality Index (AQI) and the Pollutant Standard Index (PSI) [2].

International institutions consider six major pollutants which are classified into primary and secondary categories. Nitrogen dioxide (NO2), sulfur dioxide ( $\mathrm{SO} 2)$, lead $(\mathrm{Pb}), \mathrm{CO}$, and $\mathrm{PM}_{10}$ are the primary category contaminants while ozone (O3) is a secondary category pollutant. These pollutants are measured and evaluated against the values of AQI and the quality of air may be assessed.

The AQI can be used to forecast the quality of air and to present the association of air pollution with health levels. Table 1 shows the National Ambient Air Quality Standard (NAAQS) provided by the EPA which presents the concentration of pollutants in the atmosphere. Over a 24-hour period, the Standard index (PSL) is used to measure air pollution.

Table 1. National Ambient Air Quality Standard

\begin{tabular}{|c|c|c|c|c|c|c|c|c|}
\hline \multirow{6}{*}{$\begin{array}{l}\text { Pollutant } \\
\text { standard } \\
\text { index }\end{array}$} & $\mathbf{A Q I}$ & $\begin{array}{l}\text { Air } \\
\text { quality }\end{array}$ & Pollutant & CO & $\mathrm{NO}_{2}$ & $\begin{array}{l}0_{3} \\
\text { 1-h }\end{array}$ & PM & $\mathrm{SO}_{2}$ \\
\hline & $0-50$ & Clean & \multirow{5}{*}{ 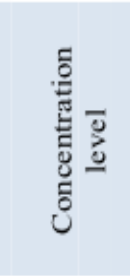 } & $0-4.5$ & - & $0-0.06$ & $0-50$ & $0-0.03$ \\
\hline & $50-100$ & Healthy & & $4.5-9$ & - & $0.06-0.12$ & $50-150$ & $0.03-0.14$ \\
\hline & $100-200$ & Unhealthy & & $9-15$ & - & $0.12-0.20$ & $150-350$ & $0.14-0.30$ \\
\hline & $200-300$ & $\begin{array}{l}\text { Very } \\
\text { unhealthy }\end{array}$ & & $15-30$ & $1.2-6$ & $0.20-0.40$ & $350-420$ & $0.30-0.60$ \\
\hline & $>300$ & Dangerous & & $>30$ & $>6$ & $>0.40$ & $>420$ & $>0.60$ \\
\hline
\end{tabular}

\subsection{Differential Optical Absorption Spectroscopy}

The Department of Environment and Natural Resources - Environmental Management Bureau (DENR-EMB) has a Differential Optical Absorption Spectroscopy (DOAS) system which is used to monitor the quality of air in different regions of the Philippines. Data obtained from the DOAS systems are evaluated and released by the DENR-EMB on their website. In Metro Manila, there are currently seven DOAS systems where some of these do not monitor the location's air quality. Though the data obtained by the DOAS is assessed by the DENR, some of these stations are inaccurate for it only measures air pollutants along a path. The pollutants and their concentrations are only quantified according to their absorption of light. Moreover, the system costs Php 3, 000, 000.00 each and is not portable since it is as huge as a container van [4]. 


\subsection{Hardware Modules}

\subsubsection{Microcontroller}

A microcontroller is a miniature computer which includes a central processing unit (CPU), a random access memory (RAM), a read-only memory (ROM), an input/output (I/O), and a timer. It is utilized for low-power and low-memory purposes. Furthermore, its memory stores the instructions or program in advance while the CPU executes these instructions. In addition, the CPU processes the input data in accordance with the instructions and enables the output of data in different forms [12]

\subsubsection{Arduino Uno}

Arduino Uno is a microcontroller board which is based on the ATmega328. It contains 14 digital I/O pins wherein six of them may be used as Pulse Width Modulation (PWM) outputs. Moreover, it also has six analog inputs, a 16-MHz crystal oscillator, a USB connection, a power jack, and an In Circuit Serial Programming header. Its power source is selected automatically which can be through a USB connection or an external power supply of $6 \mathrm{~V}$ to $20 \mathrm{~V}$. Furthermore, the ATmega328 has $32 \mathrm{~KB}$ with the allocation: $0.5 \mathrm{~KB}$ of bootloader, $2 \mathrm{~KB}$ of static random-access memory (SRAM), and $1 \mathrm{~KB}$ of electrically erasable programmable read-only memory (EEPROM) (Ausilio, 2011, p.307). Due to its miniature size and capability to connect specific modules such as Wi-fi and GPS modules, Arduino Uno can be utilized as a central processor of a $\mathrm{CO}_{2}$ and $\mathrm{NO}_{2}$ air quality monitoring system. Moreover, it may also be used as the primary component of a $\mathrm{CO}_{2}$ and $\mathrm{SNO}_{2}$ air quality monitoring system [13].

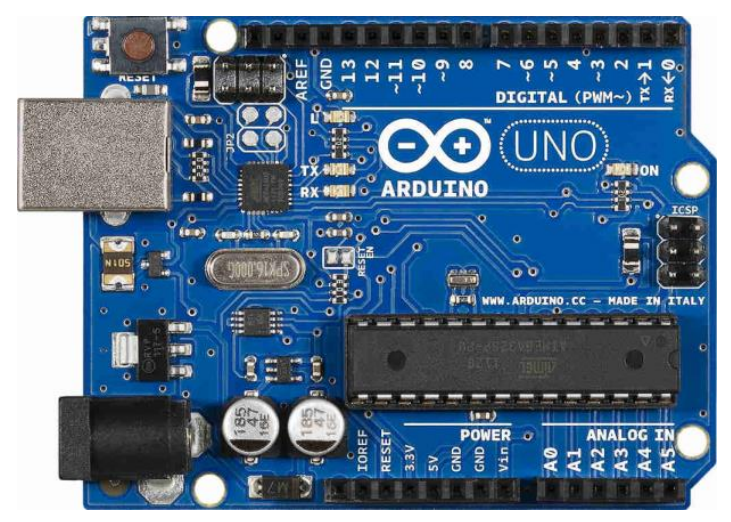

Fig.1. Arduino Uno Microcontroller

\subsubsection{Central Processing Unit}

The Central Processing Unit (CPU) is a part of the microcontroller which processes the written code (Arduino Classroom, n.d., para. 3). It is the electronic circuitry within a computer that carries out the instructions of a computer program by performing the basic arithmetic, logical, control, and input/output (I//O) operations specified by the instructions and codes [14].

\subsubsection{Carbon monoxide Gas Sensor}

The Carbon Monoxide Gas Sensor (MQ-7) can detect CO-gas concentrations from 20 to $2000 \mathrm{ppm}$. Moreover, its sensitivity can be adjusted through the potentiometer (Carbon Monoxide Gas Sensor, 2017, para. 
1). It is $40 \mathrm{~mm} \times 20 \mathrm{~mm}$ and needs $5 \mathrm{~V}$ of power supply. Moreover, it has an analog interface type and three pin definitions: signal output, power, and ground. Furthermore, the MQ-7 sensor is highly sensitive to CO and has a fast response[12].

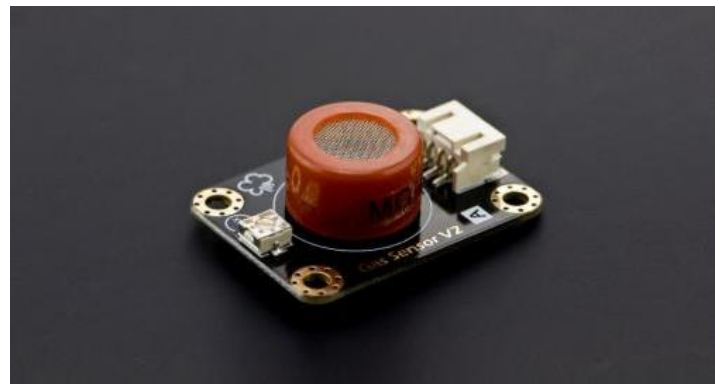

Fig.2. MQ-7 Sensor

Ambeth (2016) used an MQ-7 gas sensor with an MQ-2 gas sensor for the detection of carbon monoxide and flammable gases, respectively. The system used was able to work with a low power supply of $5 \mathrm{~V}$, unlike other systems where $24 \mathrm{~V}$ are needed for proper functioning. The sensor was able to run stably at a minimum of five years with proper calibration. To predict the concentration of gases, it did not need laboratory experiments and has a response time of 20-30 seconds. A high level of accuracy of the concentration of gases was predicted. The deviation in percentage was less than $4 \%$ for $\mathrm{CO}$ in low concentration of gases and less than $10 \%$ for methane in low concentration of gases. The deviation in percentage was found to be higher in higher concentration of gases [15].

\subsubsection{DHT22 Temperature and Humidity Sensor}

The DHT Sensor has a capacitive sensor wet component and a high-precision temperature measurement device connected to a high-performance 8-bit microcontroller. Though it is expensive, it has an excellent quality and a strong anti-jamming capability. Moreover, it is a standard single-bus interface and a quick and easy system integration.

This sensor is the best choice of all kinds of applications since it is small in size, it consumes minimal power, and it can transmit signals up to 20 meters. To meet the high demand, it can measure the temperature and humidity of the environment. It also has a good stability and high reliability (DHT22 Temperature and humidity module, 2017 , para. 2-5).

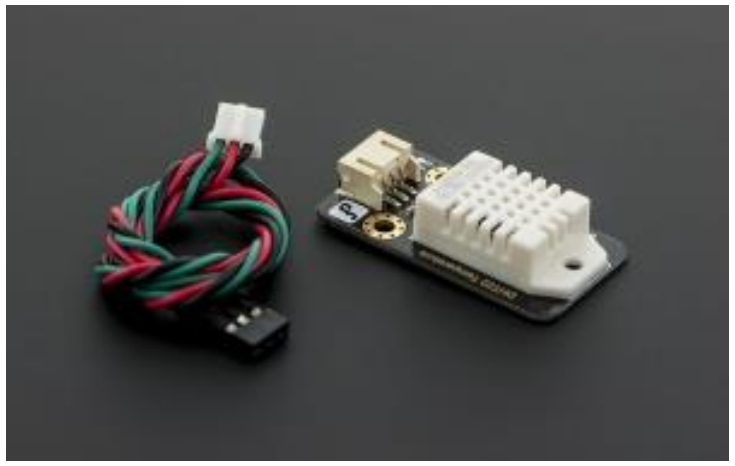

Fig.3. DHT22 Temperature and Humidity Module and Connecting Wires 
The DHT22 temperature and humidity sensor is $38 \mathrm{~mm}$ x $20 \mathrm{~mm}$. It needs a supply voltage of $5 \mathrm{~V}$ and an output voltage of $0 \mathrm{~V}$ to $3.3 \mathrm{~V}$. Moreover, it can detect temperature ranging from $-40{ }^{\circ} \mathrm{C}$ to $80{ }^{\circ} \mathrm{C}$ with an error of $< \pm 0.5^{\circ} \mathrm{C}$. It can also detect humidity ranging from $0 \%$ to $100 \%$ relative humidity (RH) with an error of $\pm 2 \% \mathrm{RH}$ (DHT22 Temperature and humidity module, 2017, para. 2-5).

Kunjumon, Pinto, and Saldanha (2016) started the Temperature and Humidity Monitoring Project where they made a system to check the accuracy of temperature at a data center through the DHT22 sensor which is based on Arduino Uno. This project made a low-cost locally available components and can be packaged into a small container. The designed project was tested a number of times and certified to achieve the aim of the project. This system can also be done with the esp8266 or different other sensors. Hence, this system is flexible and scalable [16]).

\subsubsection{Dust Sensor DSM501A}

The DSM501A dust sensor is utilized for quantitative particle (>1 micron) measurement with the principle of particle counter. Also, it can sense tobacco smoke, pollen, and house dust. Moreover, it is relatively low-cost and small in size for a particle density sensor. Furthermore, it has a light emitting diode lamp, a detector, a signal amplifier circuit, and a heater. Also, it can be used easily with a sensor PM output and can be applied to clean and purify the air [17]. In addition, Samyoung S \& C (2012) stated that the DSM501 A sensor can detect fine particles as small as $1 \mu \mathrm{m}$ when measuring the number of floating particles in a room with a maximum space of $30 \mathrm{~m}^{3}$ (p. 1).

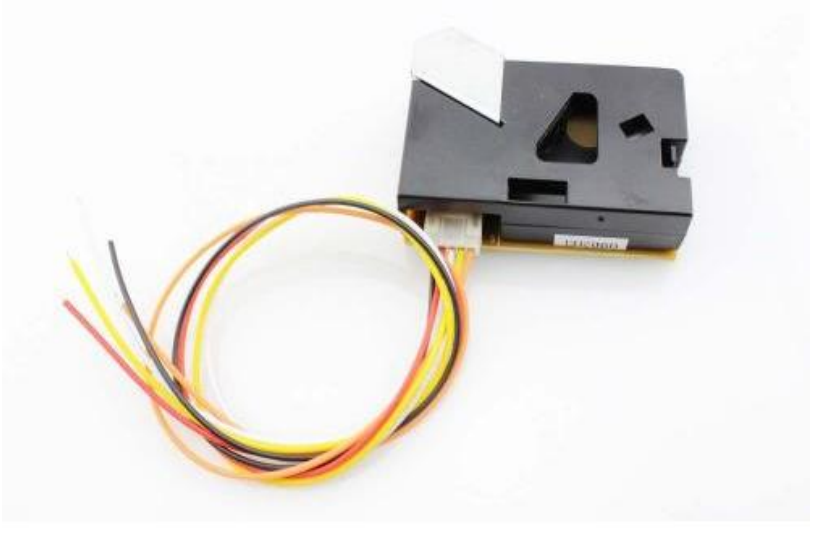

Fig.4. Dust Sensor DSM501A

In the study of Weekly et al. (2013), it was observed that local human activity, assessed through a visual camera, coincides with the concentration of coarse particles, especially those which are $\geq 2.5 \mu \mathrm{m}$. Particles in this size range may be detected by low-cost PM sensors like DSM501A. Moreover, the addition of more lowcost sensors will result in smoother data while still being economical. Real-time reporting of the PM sensor data to a central server via wireless technology is enabled by the described hardware developments which can also indicate occupancy other than being used for air quality monitoring [12].

\subsection{Internet of Things}

One of the more notable technological revolutions of this century which has been recognized is the Internet of Things (IoT). Despite the fact that it has just started, its significance has been acknowledged by major 
international standard bodies. Though it can be complex, it can be achieved with three main non-trivial architectural components: smart things, backend servers, and communications infrastructure as shown in Figure 5. In addition, the IoT does not only focus on connectivity, but it is also about the extensive collection and sharing of data towards a common goal [8].

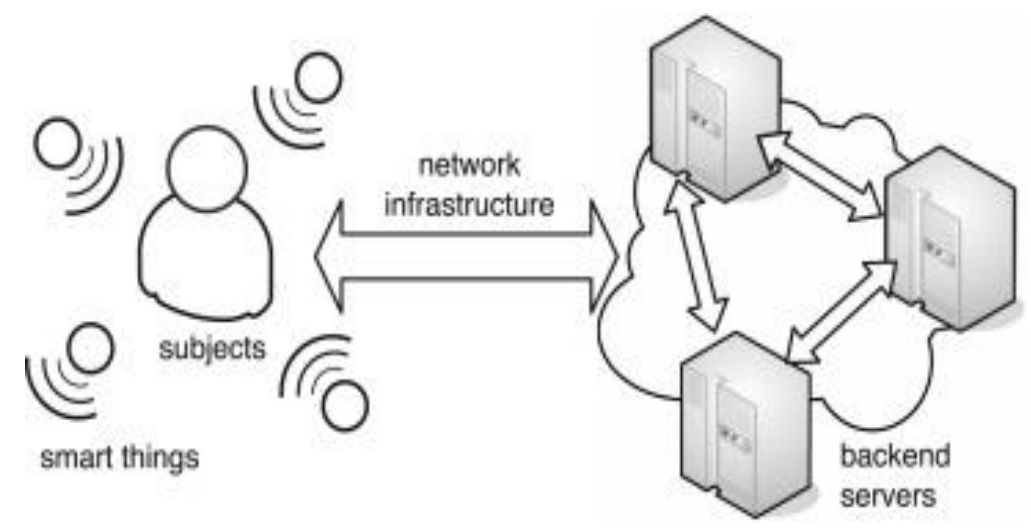

Fig.5. Simplified IoT architecture

The IoT can also be defined as a network of small, low-cost, low-power, ubiquitous electronic devices wherein sensing data and communicating information occur without direct human intervention. Each device functions as a "smart node" in the network by sensing information and performing low-level signal processing to filter signals from noise and to reduce the bandwidth needed for node-to-node communications. The nodes need to communicate with a centralized "cloud" in a secure manner to protect, store and process data, and bounce actionable information down to humans[11].

IoT is a self-configuring and adaptive system consisting of networks of sensors and smart objects whose ultimate purpose is to interconnect all things through the internet. It has connected the field of operational technology and information technology by allowing unstructured machine-generated data to be analyzed through specific algorithms and variables[4].

\subsubsection{Web Server}

Hardware-wise, a web server is generally a computer that stores all of the content files of a website. This computer would then deliver these files to an end user accessing the website. The web server is connected to and accessed through the internet. Software-wise, it contains several parts that manage how web users could access hosted files. These hosted files may be a HTTP server at the minimum. A HTTP server is a piece of software which understands URLs and HTTP. Moreover, a URL is the address of a website or web page [4].

Although there are existing commercially available air quality monitors, these monitors cost an average of Php 20, 450.00 ("[5] Moreover, they are usually large in size and are unequipped with an internet connectivity.

\subsubsection{Acer CloudProfessor}

This Acer CloudProfessor acts as a tool to combine hardware and software together for the IoT as it integrates cloud, module, device, and software terminals. Through this product, people will be able to access the IoT which will be created by inputs from devices like mobile phones or laptops (Acer_CloudProfessor, 2016). It provides freedom to choose between a variety of programming languages including Blocky and JavaScript (Acer CloudProfessor, n.d.). With this and it's service to "plug, play, code, and make", innovations created through this CloudProfessor can also be easily made by students. As Roger Wu, the Business 
Development Manager of Acer, states that "It [Acer CloudProfessor] continues to seek solutions and innovations beyond borders, honing the future leaders' creative skills and providing basic knowledge in the possibly digital future that society is anticipating." (Acer Academy, 2017).

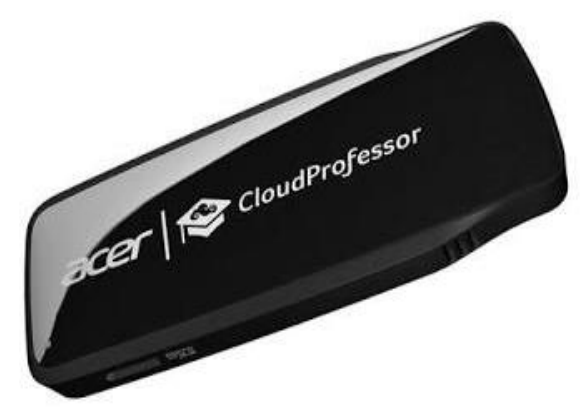

Fig.6. Acer CloudProfessor

With this, to address the problems caused by air pollution, this study aims to develop a low-cost and portable air quality monitoring system that can be accessed through the internet. It is believed that the development of this system will help communities better assess the air quality of their area.

\section{Materials and Methods}

The Iterative Design Loop method was used in the development of the air quality monitoring system. With this, the procedures were evaluated repeatedly in order to determine the effectivity of the method. For every evaluation, several iterations on the CPU, the type of sensors, and the user interface were applied to the method in order to find the optimal approach in developing the air quality monitoring system.

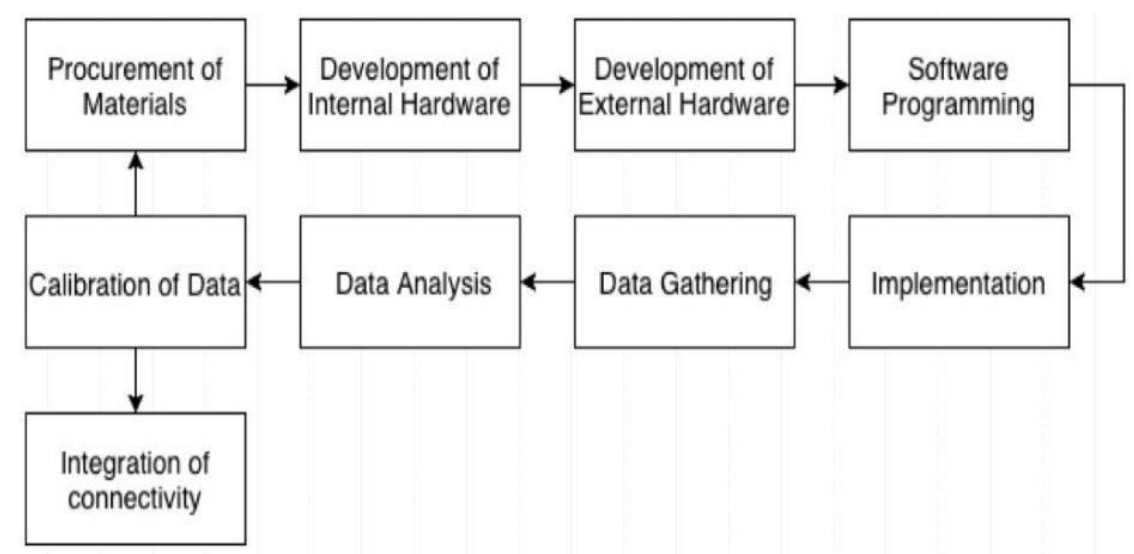

Fig.7. Interactive Design Loop Method 


\subsection{Time and Place of Study}

The development of the system was executed from October until April. Furthermore, the method was conducted at the Computer Laboratory of the Philippine Science High School - Central Luzon Campus (PSHSCLC), at DENR-EMB Region 3, and at the CCVR emission testing center located at Sto. Domingo, Angeles City, Pampanga.

\subsection{Procurement of Materials}

Majority of the prototyping tools such as the Arduino, breadboards, resistors, and wires were provided by the Computer Science Laboratory of PSHS-CLC. In addition, the Acer CloudProfessor was donated by the Department of Science and Technology. Moreover, the sensors that were used in the development of the central monitoring system including the GPRS modem, MQ-7 gas sensor, DHT22 temperature and humidity sensor, and DSM501A dust sensor were acquired from circuitrocks.com.

\subsection{Development of Internal Hardware}

The internal components of the system were linked to the circuit board electronically through conductive metal pads for the application of breadboard prototyping. The sensors, modules, and Arduino Leonardo microcontroller were placed accordingly in such a way that the connection of each sensor and the microcontroller is functioning well.

\subsection{Development of External Hardware}

The external hardware acts as the container and protection of the internal hardware system. Therefore, the design of the container minimizes and prevents external factors from altering the information from the data sensors. Furthermore, the container keeps the components well-intact in order to prevent the internal hardware from disassembling. The container is also portable given that the monitoring system will record data from different areas.

\subsection{Software Programming}

The sensors were programmed using a computer with an Arduino Integrated Development Environment (IDE). Moreover, the app and its user-interface was programmed and designed using Acer AppBuilder and Github respectively.

\subsection{Implementation}

The air quality monitoring system was tested in order to examine if the system is functioning and if the sensors are able to input data. The parameters such as CO, PM2.5, PM10, temperature, and humidity were monitored and assessed. However, the accuracy of the data will not be evaluated in this part of the study. For the DHT22 sensor testing, a hair dryer was focused on the sensor in order to generate a higher temperature. The data were then analyzed in order to know the resulting trends of the DHT22 sensor and if the obtained trend is similar to other researches. Furthermore, the testing of the MQ-7 sensor was done simultaneously with that of the DSM501A sensor. First, a paper was burnt in order to produce smoke containing CO. The CO levels were obtained using the MQ-7 sensor. Moreover, the PM levels were recorded using the DSM501A sensor. Afterwards, the trends of these values were observed in order to assess if the sensors are well- functioning.

\subsection{Data Gathering}


In order to test the efficiency of the developed air quality monitoring system and the accuracy of the data that it gathers, the developed system was placed in different monitoring sites for the different parameters it was testing. The developed and the standard air quality monitoring system gathered data simultaneously for the same period of time. For CO concentrations, the prototype was subjected to an Auto Chek smoke sensor at the CCVR emission testing center in Sto. Domingo, Angeles City, Pampanga. While PM2.5 and PM10 was placed beside the standard air quality monitoring system of the Department of Environment and Natural Resources Environmental Management Bureau (DENR-EMB) Region 3 in Balanga, Bataan. For the temperature and humidity, the prototype was placed on the Academic Building II of PSHS-CLC in high altitude and the standard data was taken from The Weather Channel.

\subsection{Welch's t-test Analysis}

The data collected by the developed air quality monitoring system and the data obtained by the standard air quality monitoring system of DENR-EMB Region 3, CCVR emission testing center, and The Weather Channel were compared through Welch's t-test or the two independent sample (unequal variance) comparison of means test. The t-test was performed in Excel and was used separately for the concentrations of CO, PM2.5, PM10, temperature, and humidity.

For each data set, the data were put in a table of two columns: $x$ and $y$. The raw data of the developed system and the standard system were placed under column $x$ and column $y$, respectively. Afterwards, the mean of each set of data was calculated. After solving for the means, we create a null hypothesis

$$
H_{o}: M_{\text {Standard }}-M_{\text {Developed }}
$$

where the means of the data sets are equal. The p-value is then solved in Excel whose tail is two-tailed and has an $\alpha=0.05$. Furthermore, to verify if it is statistically significant, the $\mathrm{p}$-value was compare to the $\alpha$. If the value was greater than the $\alpha$, then the difference of the data sets from the developed and standard monitoring system is not statistically significant. But if the p-value is less than that of the $\alpha$, them the difference statistically significant.

\subsection{Calibration of Data}

In order to test the efficiency of the developed air quality monitoring system and the accuracy of the data that it gathers, the developed system was placed in different monitoring sites for the different parameters it was testing. The developed and the standard air quality monitoring system gathered data simultaneously for the same period of time. For CO concentrations, the prototype was subjected to an Auto Chek smoke sensor at the CCVR emission testing center in Sto. Domingo, Angeles City, Pampanga. While PM2.5 and PM10 was placed beside the standard air quality monitoring system of the Department of Environment and Natural Resources Environmental Management Bureau (DENR-EMB) Region 3 in Balanga, Bataan. For the temperature and humidity, the prototype was placed on the Academic Building II of PSHS-CLC in high altitude and the standard data was taken from The Weather Channel.

\subsection{Integration of Connectivity}

Once the calibration of the proposed system was finalized, the Acer CloudProfessor was connected to the Arduino Leonardo microcontroller in order for the system to have an internet connectivity. With this, the data may be accessed through the internet with the help of Acer's App Builder. The basic block diagram of a WSN is presented in Figure 8. It shows the five basic components of the block diagram: data sensors, a processing unit, a transceiver or communicating unit, a battery power unit, and a web server [8]. 


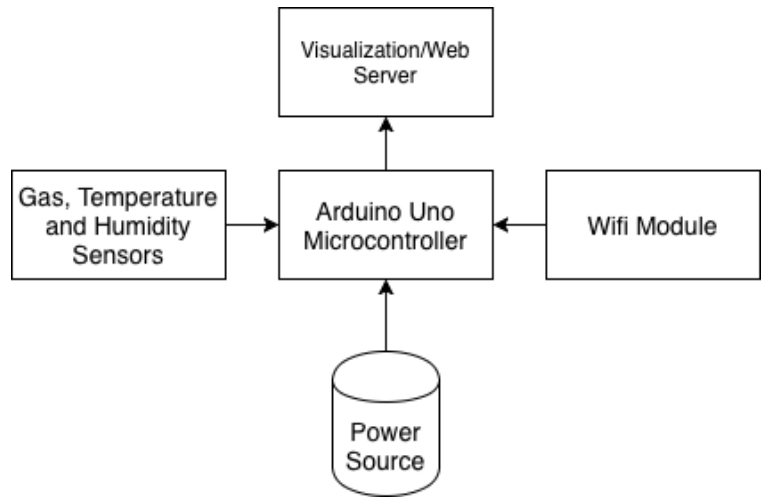

Fig.8. Basic block Diagram of a Wireless Sensor Node

\section{Results}

\subsection{Implementation}

\subsubsection{DHT22 Temperature and Humidity Sensor}

Figure 9 shows the obtained data of the DHT22 sensor after it was focused with a hair dryer. It shows that the temperature increased gradually, but started to decrease at 360 seconds when the hair dryer was removed. On the other hand, the RH\% is inversely proportional to temperature as it started to increase at 360 seconds.

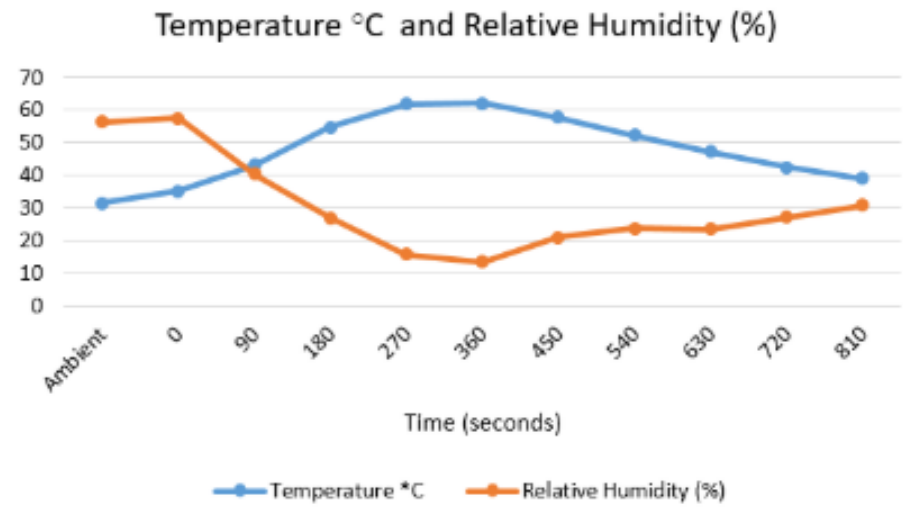

Fig.9. Data from the Implementation of the DHT22 Temperature and Humidity Sensor between Time Interval 0 to 810 Seconds

\subsubsection{MQ-7 Carbon Monoxide Sensor}

Figure 10 shows the gathered data after the subjection of the MQ-7 sensor to smoke. It exhibits that the CO levels increased at 180 seconds. Moreover, it started to decrease at 450 seconds. Furthermore, a rapid decrease in CO levels was observed at 720 seconds. 


\section{Carbon Monoxide (ppm)}

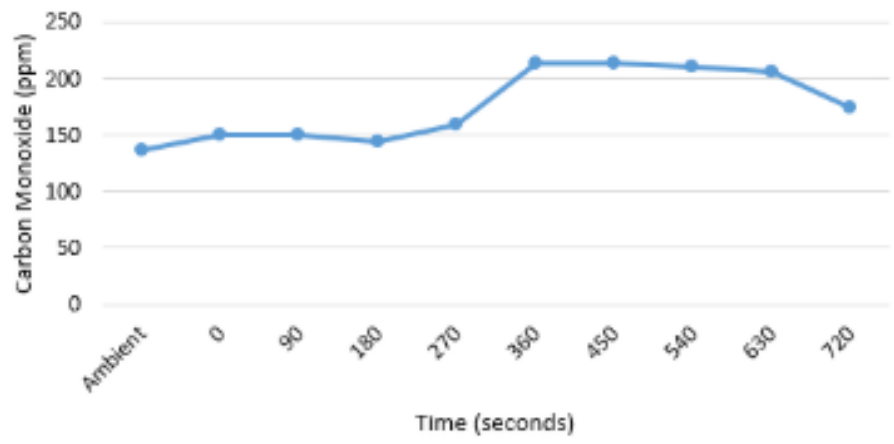

Fig.10. Data from the Implementation of the MQ-7 Carbon Monoxide Sensor between time Interval 0 to 720 Seconds

\subsubsection{DSM501A Particulate Matter Sensor}

The gathered data of the DSM501A sensor is shown in Figure 11. It shows that both PM2.5 and PM10 reached their peak at 360 seconds. However, at 720 seconds, the amount of PM2.5 decreased while the amount of PM10 increased.

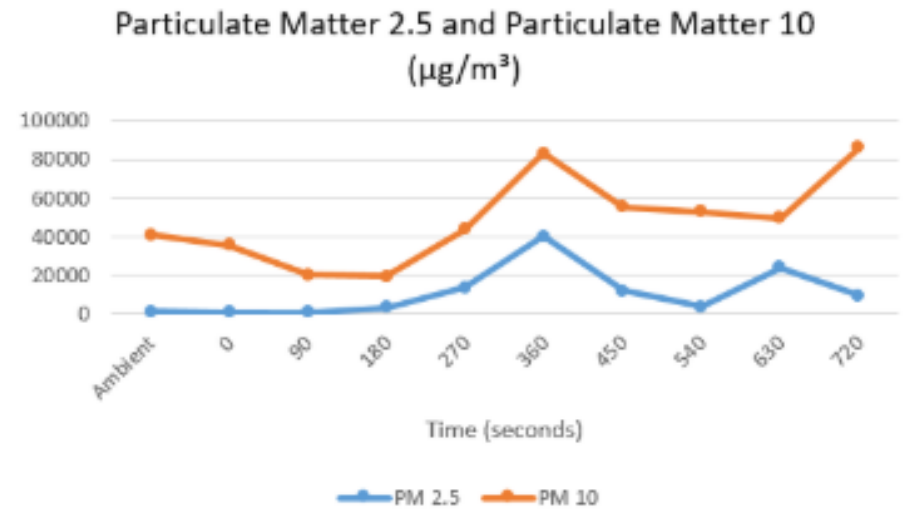

Fig.11. Data from the Implementation of the DSM501A Particulate Matter Sensor between Time Interval 0 to 720 Seconds

\subsection{Data Gathering}

\subsubsection{CO Concentration}

To get the $\mathrm{CO}$ concentration (ppm) data, the developed prototype was subjected to an Auto Chek smoke sensor for 4 hours. With this, the emission center gave the $\mathrm{CO}$ concentration that they have measured with regards to the time measured by the prototype. The gathered data is shown in Table 2 and using the t-test, the pvalue was found out to be 0.1641981697 . 
Table 2. CO Concentration (in ppm) of the Standard and the Developed air Quality Monitoring Systems

\begin{tabular}{ll}
\hline Standard (ppm) & Developed (ppm) \\
\hline $0.1138^{a}$ & $0.1^{a}$ \\
\hline
\end{tabular}

Standard $^{\mathrm{a}}$ and Developed ${ }^{\mathrm{a}}$ Belongs to the same data set of CO Concentration (ppm) of the Given time Period.

\subsubsection{Particulate Matter Concentration}

The acquisition of PM2.5 and PM10 data through the developed system had a total time length of 4 hours as shown in Table 3 and Table 4. The p-value from the t-test for PM2.5 and PM10 is 0.761555338 and 0.4710862673 , respectively.

Table 3. $\mathrm{PM}_{2.5}$ Concentration (in $\mu \mathrm{g} / \mathrm{m}^{3}$ ) of the Standard and the Developed air Quality Monitoring Systems

\begin{tabular}{ll}
\hline Standard $\left(\mu \mathrm{g} / \mathrm{m}^{3}\right)$ & Developed $\left(\mu \mathrm{g} / \mathrm{m}^{3}\right)$ \\
\hline $34.85903^{a}$ & $38.62255^{a}$ \\
\hline
\end{tabular}

Standard ${ }^{\mathrm{a}}$ and Developed ${ }^{\mathrm{a}}$ belongs to the same data set of $\mathrm{PM}_{2.5}$ Concentration $\left(\mu \mathrm{g} / \mathrm{m}^{3}\right)$ of the Given Time Period.

Table 4. PM10 Concentration (in $\mu \mathrm{g} / \mathrm{m}^{3}$ ) of the Standard and the Developed air Quality Monitoring Systems

\begin{tabular}{ll}
\hline Standard $\left(\mu \mathrm{g} / \mathrm{m}^{3}\right)$ & Developed $\left(\mu \mathrm{g} / \mathrm{m}^{3}\right)$ \\
\hline $25.71488^{a}$ & $28.85112^{a}$ \\
\hline
\end{tabular}

Standard ${ }^{\mathrm{a}}$ and Developed ${ }^{\mathrm{a}}$ Belongs to the same data set of $\mathrm{PM}_{10}$ Concentration $\left(\mu \mathrm{g} / \mathrm{m}^{3}\right)$ of the Given Time Period.

\subsubsection{Temperature and Humidity}

The data for temperature and humidity were obtained in 4 hours and 30 minutes as shown in Table 5 and Table 6. Compared to The Weather App, the p-values of temperature and humidity were 0.07511341069 and 0.4935674535 , respectively.

Table 5. Temperature (in ${ }^{\circ} \mathrm{C}$ ) of the Standard and the Developed air Quality Monitoring Systems

\begin{tabular}{ll}
\hline Standard $\left({ }^{\circ} \mathrm{C}\right)$ & Developed $\left({ }^{o} \mathrm{C}\right)$ \\
\hline $33.111^{a}$ & $33.367^{a}$ \\
\hline
\end{tabular}

Standard $^{\mathrm{a}}$ and Developed ${ }^{\mathrm{a}}$ belongs to the same data set of Temperature $\left({ }^{\circ} \mathrm{C}\right)$ of the Given Time Period.

Table 6. Relative humidity (in \%) of the Standard and the Developed air Quality Monitoring Systems

\begin{tabular}{ll}
\hline Standard (\%) & Developed (\%) \\
\hline $54.78^{a}$ & $54.33^{a}$ \\
\hline
\end{tabular}

Standard $^{\mathrm{a}}$ and Developed ${ }^{\mathrm{a}}$ belongs to the same data set of Relative Humidity (\%) of the Given Time Period. 


\subsection{Welch's t-test Analysis}

Using Welch's t-test, the data sets between the developed and standard air quality monitoring systems were analyzed. For the CO concentration, the p-value was found to be 0.1641981697 . Moreover, the obtained pvalue from the t-test of the PM2.5 and PM10 data are 0.761555338 and 0.4710862673 , respectively. Furthermore, the p-values of the temperature and humidity data are 0.07511341069 and 0.4935674535 , respectively.

\subsection{Calibration}

Through Excel, the trendline of the data sets of PM2.5 and PM10 were found. With this, the equation to convert the data from the developed system to the data from the standard system was identified. For PM2.5 and PM10, the equation from the trendline are $y=-0.000 x^{2}+0.260 x-56.84$ and $y=84.03 x^{0.16}$, respectively.

\subsection{Internet of Things}

In order to deliver real-time data to the App Builder, an Acer CloudProfessor which acted as the wifi module for the system was connected to the main Arduino microcontroller. Figure 12 shows the data displayed in the App Builder.

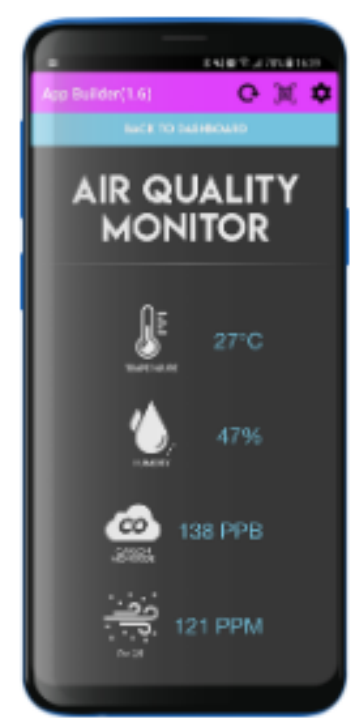

Fig.12. Mobile user Interface of the air Quality Monitoring System as shown in the AppBuilder

\section{Discussion}

\subsection{Implementation}

\subsubsection{DHT22 Temperature and Humidity Sensor}

Figure 9 shows that temperature and humidity are inversely proportional. This is supported by the findings of Jayamurugan, Kumaravel, Palanivelraja, and Chockalingam [9] which stated that temperature is negatively 
correlated with relative humidity. Furthermore, to measure the temperature, the DHT22 sensor uses a Negative Temperature Coefficient which means that the resistance decreases as the temperature increases. Due to the warm environment, the resistance of the DHT22 sensor decreases; thus, resulting to a higher temperature output [10]. For these reasons, the trends obtained from the DHT22 sensor testing are justifiable and prove that the sensor is well-functioning.

\subsubsection{MQ-7 Carbon Monoxide Sensor}

The increase in CO levels at 180 seconds in Figure 10 may be explained by the fire that had already started. Moreover, the levels began to decrease at 450 seconds as the fire started to die. Furthermore, a sudden decrease in the $\mathrm{CO}$ levels was observed at 720 seconds since the fire had already died down. The obtained results from the CO sensor testing showed a higher value from the smoke as compared to that of the ambient air. This trend may be supported by Fisher [11] who stated that there is a strong relationship between the sensor value and the CO concentration. Furthermore, the airborne sensor conductivity of the MQ- 7 sensor is positively correlated with the concentration of the $\mathrm{CO}$ gas [18]. With this, the results prove that the MQ-7 sensor is properly working as it was able to gather data and give off logical trends.

\subsubsection{DSM501A Particulate Matter Sensor}

Figure 11 shows that at 360 seconds, both PM2.5 and PM10 formed a peak since the fire is at its greatest. Moreover, at 720 seconds, PM2.5 decreased while PM10 increased. This is because PM10 is more inclusive than PM2.5 in terms of the detected diameter size of particles. As the fire died down, less small particles are in the air. Those that are left are the big ashes from the fire.

The increase in the PM values of the sensor when tested with smoke particles may be supported by the findings of DIY Projects which stated that the measured signal of the optical detector of the DSM501A sensor is proportional to the size and quantity of the suspended particulate matters [18]. In consequence, the results validate that the DSM501A sensor is working appropriately for it successfully obtained coherent data.

\subsection{Welch's t-test Analysis}

The concentrations of CO (ppm), PM2.5, PM10, temperature $\left({ }^{\circ} \mathrm{C}\right)$, and relative humidity $(\%)$, which were gathered by the developed air quality monitoring system were subjected to the Welch's t-test. These data sets were compared to standard data collected from the CCVR emission testing center, DENR-EMB Region 3, and The Weather Channel. As seen in the results, all of the p-values of CO (0.1641981697), PM2.5(0.761555338), PM10 (0.4710862673), temperature (0.07511341069), and relative humidity $(0.4935674535)$ were greater than $\alpha=0.05$. With this, the null hypothesis (Ho: Mstandard -Mdeveloped $=0$ ) is not rejected and the difference of the developed air quality monitoring system and the standard monitoring systems are not statistically significant. Therefore, the developed monitoring system is able to gather data which can be used to assess the air quality in an area.

\subsection{Calibration}

With the development of the equations for calibration of PM2.5 ( $\left.y=-0.000 x^{2}+0.260 x-56.84\right)$ and PM10 $\left(y=84.03 \mathrm{x}^{0.16}\right)$, the data that the developed system gathers was found to be more accurate when compared to the data of the standard system.

\subsection{Internet of Things}

With the connection between the Acer CloudProfessor and Arduino Leonardo microcontroller, a wireless 
sensor network was created which was able to gather, analyze, and present data wirelessly through the internet. Using Acer's App Builder, an IoT platform, this study was able to provide analytical graphs of real- time data; hence, making it more accessible to the public.

\section{Conclusion}

The study was able to successfully code and develop a cost efficient and portable air quality monitoring system that costs Php 17,605.00 as compared to the DOAS system which is approximately Php 3,000,000.00.12 Moreover, statistical analysis showed that the obtained data of the DHT22 sensor, MQ-7 sensor, and DSM501A sensor are not significantly different to that of the standard monitoring systems. Moreover, the utilization of a WSN through the use of Acer CloudProfessor enabled the monitoring system to be accessed through the internet.

It is recommended to test other gas levels that relate to air quality and air pollution such as ozone, carbon dioxide, and other gases. Moreover, it is suggested to use a cheaper and more efficient module for the utilization of IoT. In addition, it is recommended to explore other microcontrollers such as the Arduino Leonardo, Arduino Mega, and Raspberry Pi. It is also suggested that future researchers try other external casing designs to improve the device's portability and placements. Lastly, the researchers recommend that further studies provide more parameters that deal with air quality and pollution such as AQI precautions, suggestions, and air quality visual mapping system in order to provide extensive data regarding the air quality of an area.

\section{Acknowledgements}

We would like to extend our gratitudes to Mr. Joel Bautista, Ms. Josephine Joy Tolentino, Mr. Paul Jhon Diezon, Ms. Glaiza Manaloto, and Mr. Aldous Caesar Bueno for teaching us the fundamentals of research and helping us with the statistical problems we have encountered. Also, we would like to send our special regards to the Department of Environment and Natural Resources (DENR) and the CCVR emission testing center for allowing us to obtain and use data which they have measured. Finally, we would like to thank Department of Science and Technology - Science Education Institute for providing the Acer CloudProfessor used in the study.

\section{References}

[1] The World Bank. (2016). Air pollution deaths cost global economy US\$225 billion. Retrieved October 14, 2017, from http://www.worldbank.org/en/news/press-release/2016/09/08/air-pollution-deathscostglobal- economy-225-billion

[2] Department of Environment and Natural Resources. (2017). Air pollution: A public health concern in the Philippines. Retrieved December 20, 2017, from https://www.denr.gov.ph/news-and-features/latestnews/3295-air-pollution-a-public-health-concern-in-the-philippines.html

[3] Kaur N, Mahajan R, Bagai, D. (2016). Air quality monitoring system based on Arduino microcontroller. International Journal of Innovative Research in Science, Engineering, and Technology, 5(6), 9635-9646, doi:10.15680/IJIRSET.2015.0506018

[4] Wireless connectivity for IoT applications. (2015). Retrieved from http://www.st.com/content/ccc/resource/sales_and_marketing/promotional_material/brochure/d7/74/dc/e b/b4/f5/40/d5/brwireless_web.pdf/files/brwireless_web.pdf/jcr:content/translations/en.brwireless_web.p df

[5] Halil N, Abid M R, Benhaddou D, Gerndt, M. (2014). Wireless sensors networks for Internet of Things. 2014 IEEE Ninth International Conference on Intelligent Sensors, Sensor Networks and Information Processing (ISSNIP). doi:10.1109/issnip.2014.6827681 
[6] Kabashkin I, Kundler J. (2016). Reliability of sensor nodes in wireless sensor networks of cyber physical systems. Procedia Computer Science, 104, 380-384. doi:10.1016/j.procs.2017.01.149

[7] Kusrey S, Rai A, Saxena V. (2017). Zigbee based air pollution monitoring and control system using WSN. International Journal of Electronics and Communication Engineering, 4(6), 7-11. doi:10.14445/23488549/ijece-v4i6p103

[8] Jayamurugan R, Kumaravel B, Palanivelraja S, Chockalingam M P. (2013). Influence of Temperature, Relative Humidity and Seasonal Variability on Ambient Air Quality in a Coastal Urban Area. International Journal of Atmospheric Sciences, 2013, 1-7. doi:10.1155/2013/264046

[9] DHT11 \& DHT22 Sensor Temperature and Humidity Tutorial. (2016). Retrieved February 23, 2018, from https://howtomechatronics.com/tutorials/arduino/dht11-dht22-sensors-temperature-and-humiditytutorial- using-arduino/

[10] Fisher A. (2013). Characterization of MQ-series gas sensor behavior. Northern Illinois University. Retrieved from https://core.ac.uk/download/pdf/71971186.pdf

[11] Arduino MQ-7 MQ7 Digital Analog Carbon Monoxide Gas Sensor Module: Best Price in Malaysia. (n.d.). Retrieved February 23, 2018, from https://www.lelong.com.my/arduino-mq-7-mq7-digitalanalog- carbon-monoxide-gas-sensor-module-kwecommerce-200603353-2019-01-Sale-P.htm

[12] Kaur, N., Mahajan, R., \& Bagai, D. (2016). Air quality monitoring system based on Arduino microcontroller. International Journal of Innovative Research in Science, Engineering, and Technology, 5(6), 9635-9646, doi:10.15680/IJIRSET.2015.0506018

[13] Carbon Monoxide Analog Sensor MQ7 for Arduino Gravity. (n.d.). Retrieved from https://circuit.rocks/carbon-monoxide-analog-sensor-mq7-for-arduino-gravity.html

[14] Khodakarami, J. \& Ghobadi, P. (2015). Urban pollution and solar radiation impacts. Renewable and Sustainable Energy Reviews, 57, 965-976. doi:10.1016/j.rser.2015.12.166

[15] DSM501A Dust Sensor Particle Density Sensor. (n.d.). Retrieved from http://www.ailein.cc/DSM501ADust-Sensor-Particle-Density-Sensor

[16] DHT11 \& DHT22 Sensor Temperature and Humidity Tutorial. (2016). Retrieved February 23, 2018, from https://howtomechatronics.com/tutorials/arduino/dht11-dht22-sensors-temperature-and-humiditytutorial-using-arduino/

[17] Arduino MQ-7 Digital Analog Carbon Monoxide Gas Sensor Module: Best Price in Malaysia. (n.d.). Retrieved February 23, 2018, from https://www.lelong.com.my/arduino-mq-7-mq7-digital-analogcarbon-monoxide-gas-sensor-module-kwecommerce-200603353-2019-01-Sale-P.htm

[18] DIY Projects. (2017). Calculate the Air Quality Index (IAQ, IQA) with a DSM501 on Arduino or ESP8266. (2017, October 13). Retrieved February 23, 2018, from https://diyprojects.io/calculate-airquality- index-iaq-iqa-dsm501-arduino-esp8266/\#.WpAMAahubIU

\section{Authors' Profiles}

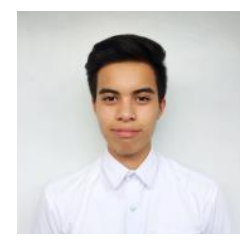

Louis Anton A. Cruz is currently a 12th grade student at the Philippine Science High School - Central Luzon Campus located in Pampanga, Philippines. He is taking the Science, Technology, Engineering, and Mathematics academic strand and is expected to graduate from high school at the end of May 2019. 


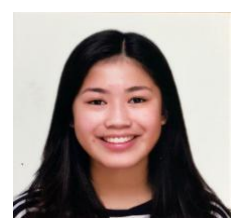

Maria Teresa T. Grino is currently a 12th grade student at the Philippine Science High School - Central Luzon Campus located in Pampanga, Philippines. He is taking the Science, Technology, Engineering, and Mathematics academic strand and is expected to graduate from high school at the end of May 2019.

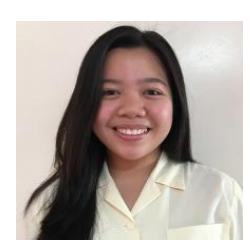

Thea Marie V. Tungol is currently a 12th grade student at the Philippine Science High School - Central Luzon Campus located in Pampanga, Philippines. He is taking the Science, Technology, Engineering, and Mathematics academic strand and is expected to graduate from high school at the end of May 2019.

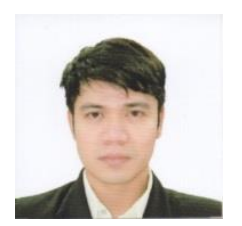

Joel T. Bautista is currently a Computer Science teacher at the Philippine Science High School - Central Luzon Campus. He completed his Academic Requirements for the Doctor of Technology program at the Technological University of the Philippines.

How to cite this paper: Louis Anton A. Cruz, Maria Teresa T. Griño, Thea Marie V. Tungol, Joel T. Bautista,"Development of a Low-Cost Air Quality Data Acquisition IoT-based System using Arduino Leonardo", International Journal of Engineering and Manufacturing(IJEM), Vol.9, No.3, pp.1-18, 2019.DOI: 10.5815/ijem.2019.03.01 